\title{
Denise Klein
}

Die osmanischen Ulema des 17. Jahrhunderts 


\title{
ISLAMKUNDLICHE UNTERSUCHUNGEN • BAND 274
}

\author{
begründet \\ von Klaus Schwarz \\ herausgegeben \\ von Gerd Winkelhane
}


ISLAMKUNDLICHE UNTERSUCHUNGEN • BAND 274

\author{
Denise Klein
}

Die osmanischen Ulema des 17. Jahrhunderts

Eine geschlossene Gesellschaft? 
Bibliografische Information der Deutschen Bibliothek

Die Deutsche Bibliothek verzeichnet diese Publikation in der

Deutschen Nationalbibliografie; detaillierte bibliografische Daten

sind im Internet über http://dnb.ddb.de abrufbar.

\section{British Library Cataloguing in Publication data}

A catalogue record for this book is available from the British Library.

http://www.bl.uk

Library of Congress control number available

http://www.loc.gov

Alle Rechte vorbehalten. Kein Teil dieses Buches darf in irgendeiner Form (Druck, Fotokopie oder einem anderen Verfahren) ohne schriftliche Genehmigung des Verlages reproduziert oder unter Verwendung elektronischer Systeme verarbeitet werden.

(C) 2007 by Klaus Schwarz Verlag GmbH Erstausgabe

1. Auflage

Layout und Herstellung: J2P Berlin

Gedruckt auf chlorfrei gebleichtem Papier

Printed in Germany

ISBN 978-3-87997-337-8 